University of Nebraska - Lincoln

DigitalCommons@University of Nebraska - Lincoln

Faculty Publications in Food Science and Technology

2005

Evaluation of Liquid Nitrogen Freeze Drying and Ethanol

Dehydration as Methods to Preserve Partially Cooked Starch and

Masa Systems

Roxana Yglesias

University of Nebraska-Lincoln

David S. Jackson

University of Nebraska-Lincoln, djackson1@unl.edu

Follow this and additional works at: https://digitalcommons.unl.edu/foodsciefacpub

Part of the Food Science Commons

Yglesias, Roxana and Jackson, David S., "Evaluation of Liquid Nitrogen Freeze Drying and Ethanol Dehydration as Methods to Preserve Partially Cooked Starch and Masa Systems" (2005). Faculty

Publications in Food Science and Technology. 101.

https://digitalcommons.unl.edu/foodsciefacpub/101

This Article is brought to you for free and open access by the Food Science and Technology Department at DigitalCommons@University of Nebraska - Lincoln. It has been accepted for inclusion in Faculty Publications in Food Science and Technology by an authorized administrator of DigitalCommons@University of Nebraska - Lincoln. 


\title{
Evaluation of Liquid Nitrogen Freeze Drying and Ethanol Dehydration as Methods to Preserve Partially Cooked Starch and Masa Systems ${ }^{1}$
}

\author{
Roxana Yglesias² and David S. Jackson ${ }^{2,3}$
}

ABSTRACT

Cereal Chem. 82(6):702-705

\begin{abstract}
Preservation of starch structure/properties, including structures formed during partial or complete cooking, are important when the impact of processing conditions is being studied. Two preservation techniques used to study changes in starch during thermal-mechanical processing are commonly cited in the literature: 1) rapid freezing followed by lyophilization, and 2) a dehydration procedure using alcohols. A comparative determination on how these methods affect various starch structures has not been widely reported. Corn starch samples were collected from the Rapid Visco-Analyser (RVA) at $3 \mathrm{~min}$ (swollen granules, $30^{\circ} \mathrm{C}$ ), at the top of the pasting peak (gelatinized granules, $95^{\circ} \mathrm{C}$ ), at the bottom of the trough (dispersed polymers, $95^{\circ} \mathrm{C}$ ), and a completed RVA sample stored
\end{abstract}

for $120 \mathrm{hr}$ at $4^{\circ} \mathrm{C}$ (retrograded starch). Samples of masa were obtained by nixtamalizing corn. Differential scanning calorimetry (DSC) endotherms of starch and masa, and X-ray diffraction (XRD) patterns of masa were evaluated after being preserved by alcohol- or freeze-drying. No significant differences $(P>0.05)$ between methods were found for onset, end, and peak temperatures $\left({ }^{\circ} \mathrm{C}\right)$, enthalpy $(\mathrm{J} / \mathrm{g})$ and $\%$ relative crystallinity in any of the samples analyzed. Liquid nitrogen freeze-drying and ethanol dehydration are both effective methods of preserving various starch systems for structural changes detectible by DSC and XRD; freeze-drying is generally less expensive and time-consuming.
Staling is a significant problem in corn tortillas. Aged tortillas are firmer, more rigid, and less rollable than fresh tortillas (Suhendro et al 1998). To prevent or retard staling, several investigations have tried to elucidate how tortillas stale (Fernandez-DeCastro 1988; Hebeda et al 1991; Friend et al 1993; Yau et al 1994; Fernandez et al 1999). Starch is the major component ( $\approx 80 \% \mathrm{db}$ ) in corn tortillas (Fernandez et al 1999). Therefore, attempts to explain staling by characterizing starch physical and chemical changes during storage have been made (Ghiasi et al 1979; Martin et al 1991; Ruan et al 1996). Due to the rapid and substantial changes in starch structures in the first hours after corn tortillas are cooked (Fernandez et al 1999), it is vital to preserve and stabilize starch properties and characteristics for accurate analysis and study. In general, there are two methods widely used for this purpose: 1) rapid freezing followed by lyophilization (freezedrying), and 2) a dehydration procedure using ethanol (Fernandez et al 1999). Very little is known about the effect these treatments have, if any, on starch. Some researchers believe that the process of lyophilization causes gelatinized molecules to retrograde with consequent changes in the properties of the starch being evaluated. Retrogradation has been used to describe starch structural changes following gelatinization (Cameron and Donald 1991) and also as a stage of increased order (degree of crystallinity) from initially dispersed starch molecules (Atwell et al 1988). Differential scanning calorimetry (DSC) and X-ray diffraction methods are widely used as tools to investigate the order-disorder transitions that occur to an aqueous suspension of starch granules upon heating (Eliasson 1985; Cameron and Donald 1991; Liu et al 1992).

Masa can be considered a system of solubilized starch polymers supporting uncooked, swollen, dispersed, and retrograded starch granules (Gomez et al 1990).

This work was designed not only to study masa as a network of different starch organizations but to be able to investigate each molecular starch structure individually. A starch model system was generated for this purpose and samples of swollen, gelatinized, dispersed, and retrograded corn starch granules were investigated.

\footnotetext{
'A contribution of the University of Nebraska Agriculture Research Division, Lincoln, NE 68583. Journal Series No. 14870.

${ }^{2}$ Former graduate research assistant and professor, respectively, Department of Food Science and Technology, University of Nebraska, Lincoln, NE 685830919.

${ }^{3}$ Corresponding author. Fax: 402-472-1693. E-mail: djackson@unlnotes.unl.edu
}

DOI: $10.1094 / C C-82-0702$

(C) 2005 AACC International, Inc.
Thermal properties of samples measured by DSC, and relative crystallinity quantified by X-ray diffraction of nixtamalized masa and the starch model system were studied as affected by the two preservation methods described above.

\section{MATERIALS AND METHODS}

\section{Sample Preparation of Starch and Masa Systems}

Slurries of native corn starch (3.85 g of starch and $25.15 \mathrm{~g}$ of water) were loaded into a Rapid Visco-Analyser (RVA). The scan profile used started at $30^{\circ} \mathrm{C}$ (held for $10 \mathrm{~min}$ ), ramped to $95^{\circ} \mathrm{C}$ (in $6 \mathrm{~min}$ ), and was maintained at $95^{\circ} \mathrm{C}$ for $5 \mathrm{~min}$. Samples were cooled to $50^{\circ} \mathrm{C}$ (in $4 \mathrm{~min}$ ) and held at $50^{\circ} \mathrm{C}$ for $10 \mathrm{~min}$. The RVA paddle was programmed to turn at $160 \mathrm{rpm}$ to help mix the sample. Swollen granules, gelatinized, dispersed, solubilized, and retrograded starch were obtained by collecting four samples from the RVA profile 1) at $3 \mathrm{~min}, 2)$ at the viscosity peak (16.06 min), 3 ) at the trough $(21.16 \mathrm{~min})$, and 4) a completed RVA sample stored for $120 \mathrm{hr}$ at $4^{\circ} \mathrm{C}$, respectively. Every $29 \mathrm{~g}$ of RVA starch/water system sample was divided in two 14.5-g subsamples. Each subsample was placed in two $50-\mathrm{mL}$ disposable/ graduated centrifuge tubes with screw caps until preserved $(\approx 7$ $\mathrm{g} /$ container).

Masa was prepared using a small-scale laboratory technique. Clean corn $(500 \mathrm{~g})$ was cooked at $90^{\circ} \mathrm{C}$ for $30 \mathrm{~min}$ in a $2,000-\mathrm{mL}$ glass beaker with $1,500 \mathrm{~mL}$ of water and $5 \mathrm{~g}$ of food-grade lime $\mathrm{Ca}(\mathrm{OH})_{2}$, (Mississippi Lime Co., Alton, IL). Corn was steeped for $8.5 \mathrm{hr}$, rinsed twice using $700 \mathrm{~mL}$ of water per wash, drained and ground into masa dough with a small-scale stone grinder as generally described by Yglesias et al (2005).

Samples of the starch model system and masa were preserved within the first $5 \mathrm{~min}$ after they were prepared. The order in which each sample was preserved with a given method was randomly assigned.

\section{Starch Preservation by Liquid Nitrogen Freeze-Drying}

Two centrifuge tubes containing a sample of the starch model system (total of $14.5 \mathrm{~g} / \mathrm{sample}$ ) or $30 \mathrm{~g}$ of nixtamalized masa were placed in a $600 \mathrm{~mL}$ wide-mouth freeze-drying flask (The VirTis Co., Gardiner, NY) with $\approx 300 \mathrm{~mL}$ of liquid nitrogen until completely frozen. Flasks were connected to an $8 \mathrm{~L}$ benchtop freezedrier (VirTis) at $-50^{\circ} \mathrm{C}$ for $24 \mathrm{hr}$. Samples were then ground using a cyclone sample mill with a $1-\mathrm{mm}$ mesh screen (model $3010-$ 030, Udy Corp., Fort Collins, CO) for further analysis. 


\section{Starch Preservation by Ethanol Dehydration}

Two centrifuge tubes of each starch sample $(\approx 7 \mathrm{~g} /$ container $)$ or four centrifuge tubes for each $30 \mathrm{-g}$ nixtamalized masa subsample $(\approx 7.5 \mathrm{~g} /$ container $)$ were filled with $30 \mathrm{~mL}$ of $100 \%$ ethanol. Slurries were transferred to a mortar, manually ground for $1 \mathrm{~min}$, and replaced in the containers. Tubes were shaken manually for $1 \mathrm{~min}$ and centrifuged for $10 \mathrm{~min}$ at $3,400 \times g$. The supernatant was discarded and the pellet was extracted again. Solids were dried in a forced-air oven (model 1350F, Sheldon Manufacturing, Cornelius, OR) at $45^{\circ} \mathrm{C}$ for $2 \mathrm{hr}$ as specified by Fernandez et al (1999). Samples were then ground before analysis using the same cyclone sample mill used for freeze-dried samples.

\section{DSC Analysis}

Thermal properties of masa and starch samples, after being preserved by liquid nitrogen-freeze drying or ethanol dehydration, were investigated using a differential scanning calorimetry (Pyris 1, Perkin Elmer Co., Norwalk, CT). Samples $(\approx 10 \mathrm{mg})$ were accurately weighed into stainless steel pans and hydrated with $55 \mu \mathrm{L}$ of distilled water to $\approx 80 \%$ moisture content. Pans were sealed and stored at room temperature $\left(23 \pm 2^{\circ} \mathrm{C}\right)$ for $\approx 12 \mathrm{hr}$. Endotherms were obtained after heating the aluminum pans from 30 to $110^{\circ} \mathrm{C}$ at a rate of $5^{\circ} \mathrm{C} / \mathrm{min}$. Onset temperature $\left({ }^{\circ} \mathrm{C}\right)$, peak temperature $\left({ }^{\circ} \mathrm{C}\right)$, end temperature $\left({ }^{\circ} \mathrm{C}\right)$, and enthalpies $(\mathrm{J} / \mathrm{g})$ were calculated by endotherm peak analysis.

\section{X-ray Diffraction}

$\mathrm{X}$-ray diffraction patterns were obtained using an X-ray diffractometer (D-Max/B Horizontal Q/2Q, Rigaku Denki Co.,
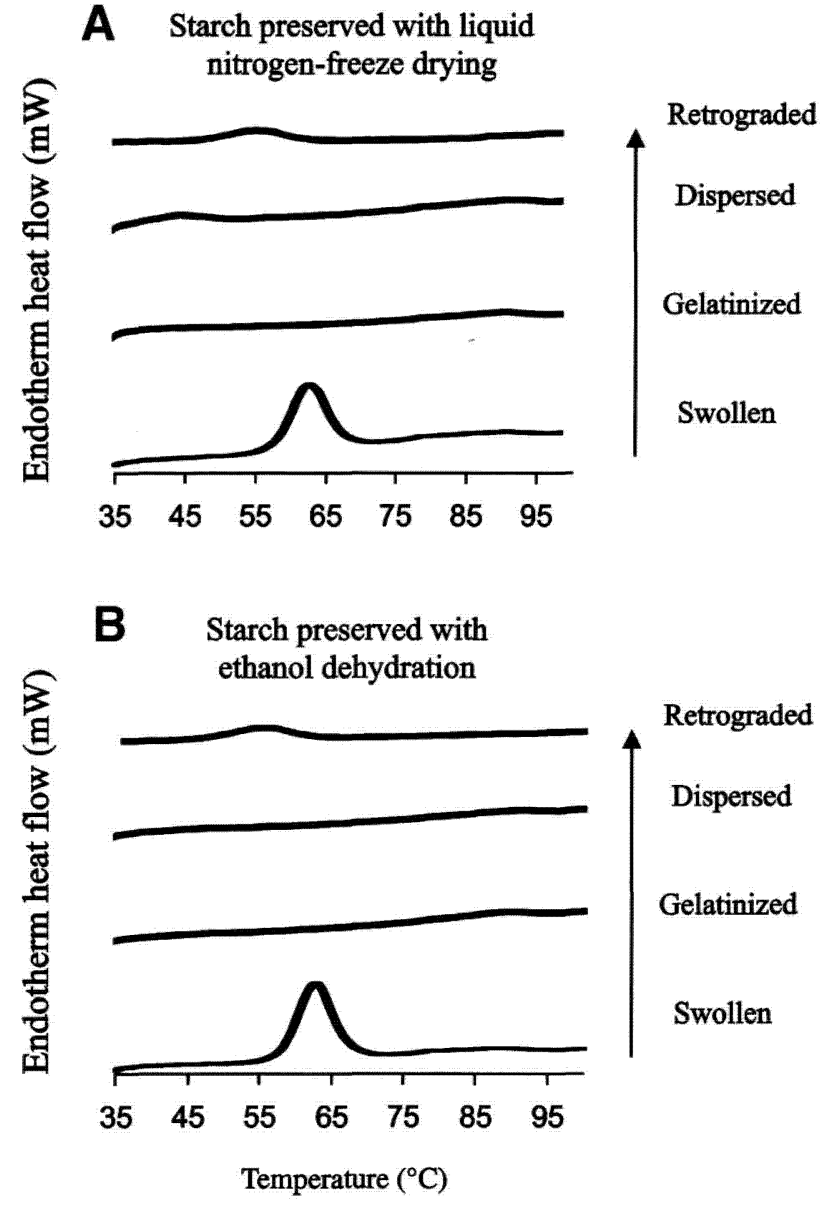

Fig. 1. Representative DSC endotherms for the starch model system after being preserved by liquid nitrogen-freeze drying and by ethanol dehydration.
Japan). Masa samples were placed in a zero-cavity flat-mount glass and a metal spatula was used to even out the sample thickness; $100 \%$ ethanol was added to fix it to the mount. Slides were placed into a sample holder inside the diffractometer and scanned from $2 \theta=3-30^{\circ}$ with $2 \% \mathrm{~min}$ increments. The X-ray diffractometer was operated at $40 \mathrm{kV}$ tube voltage and at $30 \mathrm{~mA}$ tube current. Diffraction patterns were analyzed using MacDiff X-ray diffraction peak analysis software (v. 4.2.5, Geologisch-Paläontologisches Institut, Frankfurt, Germany). The lower points of the diffraction peaks were connected by a smooth curve (crystallinity line). Area under the peaks, but over the crystallinity line, was estimated as the crystalline component. A baseline connecting the starting and end points of the crystallinity line was traced to estimate the area corresponding to the amorphous region; the amorphous region was the area between the crystallinity line and the baseline. Percentage of relative crystallinity was calculated by dividing the area of the crystalline region by the area of the amorphous region (Roe 2000).

\section{Statistical Analysis}

The starch model system was analyzed as a split-plot where type of starch structure (swollen, gelatinized, dispersed, and retrograded) was the whole plot and preservation method (liquid nitrogen freeze-drying and ethanol dehydration) was the split-plot factor. The experiment was repeated three times and the analysis of variance performed with SAS Proc Mixed, adjusting degrees of freedom for testing by the Satterthwaite's approximation (Mead 1988). Means were separated using the lsmeans procedure (v. 8, SAS Institute, Cary, NC). Masa was analyzed as a randomized complete block design (RCBD) where the masa production batches were the blocking factor and preservation methods the treatments. The experiment was repeated three times. The analysis of variance was run using SAS Proc Mixed, and means separated with lsmeans procedure.

\section{RESULTS AND DISCUSSION}

\section{Starch Model System}

Thermal properties of representative samples of the starch model system are shown in Fig. 1. Swollen granules showed a peak at $\approx 62^{\circ} \mathrm{C}$, indicating melting of the crystallites or double helices within the range expected for corn starch gelatinization (Morris 1990; Sahai 1999). Gelatinized and dispersed starch granule samples showed no peak at this temperature, which is evidence of com-

TABLE I

DSC Thermal Properties Means, Standard Errors, and $P$ Values Comparing Starch Swollen Granules by Method of Preservation ${ }^{\text {a }}$

\begin{tabular}{lcccc}
\hline & \multicolumn{3}{c}{ Temperature $\left({ }^{\circ} \mathbf{C}\right)$} & \\
\cline { 2 - 4 } Treatment & Onset & Peak & End & Enthalpy $(\mathbf{J} / \mathbf{g})$ \\
\hline Liquid nitrogen-freeze drying & 58.03 & 62.33 & 66.40 & 11.10 \\
Ethanol dehydration & 58.16 & 62.51 & 65.68 & 11.67 \\
Standard error & 0.42 & 0.53 & 0.98 & 0.51 \\
$P$ value & 0.9110 & 0.1334 & 0.4891 & 0.8950 \\
\hline
\end{tabular}

a Mean values for three treatment replicates.

TABLE II

DSC Thermal Properties Means, Standard Errors, and $\boldsymbol{P}$ Values Comparing Retrograded Starch by Method of Preservation ${ }^{a}$

\begin{tabular}{lcccc}
\hline & \multicolumn{3}{c}{ Temperature $\left({ }^{\circ} \mathbf{C}\right)$} & \\
\cline { 2 - 4 } Treatment & Onset & Peak & End & Enthalpy $(\mathbf{J} / \mathbf{g})$ \\
\hline Liquid nitrogen-freeze drying & 47.26 & 54.87 & 61.61 & 4.08 \\
Ethanol dehydration & 47.53 & 56.39 & 64.45 & 3.71 \\
Standard error & 0.42 & 0.53 & 0.98 & 0.51 \\
$P$ value & 0.9110 & 0.1334 & 0.4891 & 0.8950 \\
\hline
\end{tabular}

${ }^{a}$ Mean values for three treatment replicates. 
plete gelatinization. A peak at $\approx 55^{\circ} \mathrm{C}$ for the retrograded starch endotherm illustrates the retrograded amylopectin crystal melting site as established by other authors (Fernandez et al 1999; Seetharaman et al 2002). These data demonstrate that specific starch structures at the phases investigated (swollen, gelatinized, dispersed, and retrograded) can be successfully obtained from an appropriately programmed RVA instrument.

Means and standard errors for DSC thermal properties for swollen and retrograded starch are shown in Tables I and II, respectively. $P$ values for all the variables measured showed no differences $(P>0.05)$ when comparing the two methods of starch preservation. There were no detectable endotherms for gelatinized and dispersed starch. These findings demonstrate that for individual molecular forms (swollen, gelatinized, dispersed, and retrograded), liquid nitrogen-freeze drying and ethanol dehydration are equally appropriate in preserving characteristics for further analysis.

\section{Masa Systems}

Starch gelatinization during alkaline cooking and steeping is restricted by insufficient heat and moisture (Gomez et al 1992) and by amylose-calcium interactions (Robles et al 1988). Masa can be considered to be a network of solubilized starch polymers supporting uncooked, swollen, and dispersed starch granules (Gomez et al 1990). In addition, retrogradation of gelatinized starch granules takes place very rapidly upon masa cooling; DSC traces have previously shown melting of an amylose-lipid complex peak at $\approx 95^{\circ} \mathrm{C}$, and after storage, an amylopectin recrystallization peak at $\approx 55^{\circ} \mathrm{C}$ (Seetharam et al 2002). None of these retrogradation peaks were observed in this study; presumably there was insufficient time for molecules to reorganize, as starch preser-

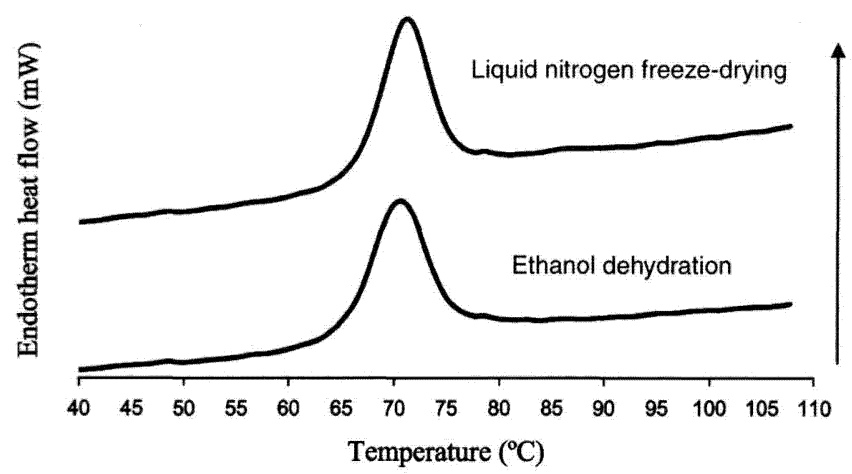

Fig. 2. Representative DSC endotherm for nixtamalized masa after being preserved by liquid nitrogen-freeze drying and ethanol dehydration.

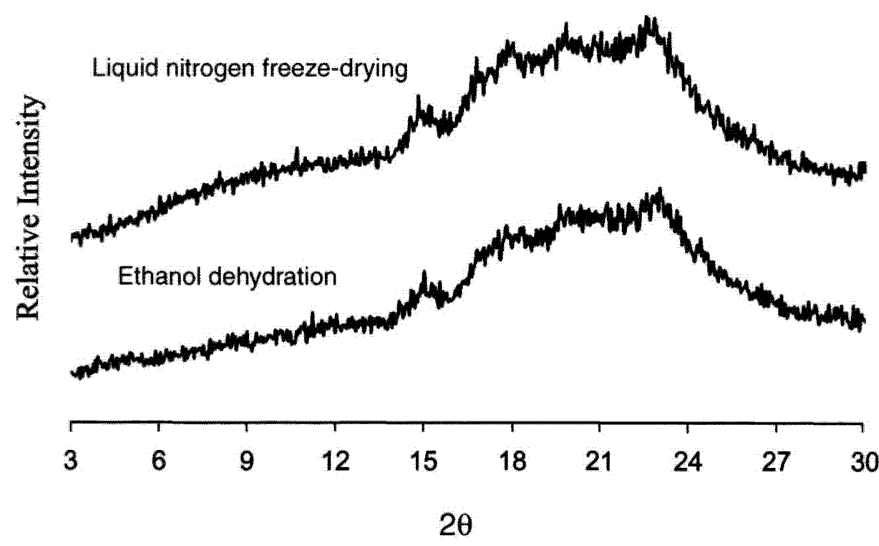

Fig. 3. Representative X-ray A-type diffraction pattern for nixtamalized masa after being stabilized and preserved by liquid nitrogen freeze-drying and ethanol dehydration. vation methods were started when masa was still warm (first 10 min after grinding). Figure 2 shows representative DSC endotherms for nixtamalized masa. The peak at $\approx 69^{\circ} \mathrm{C}$ is indicative of starch gelatinization.

One of the other starch forms thought to exist in masa is annealed starch (Gomez et al 1990). Annealing takes place during steeping as starch is heated in excess water for a period of time at subgelatinization temperatures (Gomez et al 1992). This alteration within the masa crystallites can explain the increase in masa gelatinization temperature $\left(\approx 69^{\circ} \mathrm{C}\right.$, Table III), when compared to native corn starch $\left(\approx 62^{\circ} \mathrm{C}\right.$, Table I). Krueger et al (1987) suggested that annealing of starch caused a higher maximum temperature of gelatinization. It is also possible that this increase in temperature is solely due to the fact that the starches being compared are from different sources.

Gomez et al (1989) observed that crystallinity of corn starch decreased during tortilla processing. However, they did not find differences in A-type diffraction patterns of nixtamal and masa even though nixtamal was exposed to high mechanical shearing and warm temperatures during grinding into masa. Figure 3 shows A-type diffraction patterns for nixtamalized masa after being preserved by liquid nitrogen freeze-drying or ethanol dehydration. No significant differences were found in relative crystallinity (Table IV).

These findings support the hypothesis that neither liquid nitrogen freeze-drying nor ethanol dehydration caused significant alterations in starch molecular structures detectable by DSC or XRD.

\section{CONCLUSIONS}

Both liquid nitrogen freeze-drying and ethanol dehydration were effective methods for starch stabilization/preservation of properties detected during DSC and XRD analysis. These procedures can be used to preserve starch molecular structures at a specific point in time. Ethanol dehydration does not need sophisticated equipment but involves several analytical steps that logistically complicate evaluation of sequential samples. Running multiple tests on closely time-dependant samples requires increasing numbers of trained personnel. Liquid nitrogen freezing followed by freeze-drying is a simple and efficient procedure that allows studying samples taken at short time intervals. The method, however, requires a freeze drier and is limited by the freeze drier capacity. The starch preservation method to select will depend on the scope of the research project and resource availability.

TABLE III

DSC Thermal Properties Means, Standard Errors, and $P$ Values of Nixtamalized Masa by Method of Preservation ${ }^{a}$

\begin{tabular}{lcccc}
\hline & \multicolumn{3}{c}{ Temperature $\left({ }^{\circ} \mathbf{C}\right)$} & \\
\cline { 2 - 4 } Treatment & Onset & Peak & End & Enthalpy $(\mathbf{J} / \mathbf{g})$ \\
\hline Liquid nitrogen-freeze drying & 65.24 & 69.72 & 74.37 & 6.12 \\
Ethanol dehydration & 65.12 & 69.83 & 75.00 & 6.63 \\
Standard error & 0.21 & 0.25 & 0.39 & 0.62 \\
$P$ value & 0.7246 & 0.7654 & 0.3687 & 0.6197 \\
\hline
\end{tabular}

${ }^{a}$ Mean values for three treatment replicates.

TABLE IV

Means, Standard Error, and $\boldsymbol{P}$ Value for Relative Crystallinity of Nixtamalized Masa by Method of Preservation ${ }^{a}$

\begin{tabular}{lc}
\hline Treatment & Relative Crystallinity $(\%)$ \\
\hline Liquid nitrogen-freeze drying & 30.05 \\
Ethanol dehydration & 27.72 \\
Standard error & 0.92 \\
$P$ value & 0.6633 \\
\hline
\end{tabular}

${ }^{a}$ Mean values for three treatment replicates. 


\section{LITERATURE CITED}

Atwell, W. A., Hood, L. F., Lineback, D. R., Varriano-Marston, E., and Zobel, H. F. 1988. The terminology and methodology associated with basic starch phenomena. Cereal Foods World 33:306-311.

Cameron, R. E., and Donald, A. M. 1991. Small-angle X-ray scattering and differential scanning calorimetry from starch and retrograded starch. Pages 301-309 in: Food Polymers, Gels and Colloids. E. Dickinson, ed. R. Soc. Chem.: Cambridge, UK.

Eliasson, A. C. 1985. Retrogradation of starch as measured by differential scanning calorimetry. Pages 93-98 in: New Approaches to Research on Cereal Carbohydrates. R. D. Hill, L. Munck, eds. Elsevier: Amsterdam.

Fernandez, D. A., Waniska, R. D., and Rooney, L. W. 1999. Changes in starch properties of corn tortillas during storage. Starch 51:136-140.

Fernandez-DeCastro, D. 1988. Staling in corn tortillas prepared from nixtamalized corn flour. MS thesis. Texas A\&M University: College Station, TX.

Friend, C. P., Waniska, R. D., and Rooney, L. W. 1993. Effects of hydrocolloids on processing and qualities of wheat tortillas. Cereal Chem. 70:252-256.

Ghiasi, K., Hoseney, R. C., and Lineback, R. C. 1979. Characterization of soluble starch from bread crumb. Cereal Chem. 56:485-489.

Gomez, M. H., McDonough, C. M., Rooney, L. W., and Waniska, R. D. 1989. Changes in corn and sorghum during nixtamalization and tortilla baking. J. Food Sci. 54:330-335.

Gomez, M. H., Waniska, R. D., and Rooney, L. W. 1990. Effects of nixtamalization and grinding conditions on the starch in masa. Starch 42:475-479.

Gomez, M. H., Lee, J. K., McDonough, C. M., Waniska, R. D., and Rooney, L. W. 1992. Corn starch changes during tortilla and tortilla chip processing. Cereal Chern. 69:275-279.

Hebeda, R. E., Bowles, L. K., and Teague, W. M. 1991. Use of intermediate temperature stability enzymes for retarding staling in baked goods. Cereal Foods World 38:619.
Krueger, B. R., Knutson, C. A., Inglett, G. E., and Walker, C. E. 1987. A differential scanning calorimetry study on the effect of annealing on gelatinization behavior of corn starch. J. Food Sci. 52:715-718.

Liu, H., and Leliévre, J. 1992. A differential scanning calorimetry study of melting transitions in aqueous suspensions containing blends of wheat and rice starch. Carbohydr. Res. 210:79-87.

Martin, M. L., Zeleznak, K. J., and Hoseney, R. C. 1991. A mechanism of bread firming. I. Role of starch swelling. Cereal Chem. 68:498-503.

Mead, R. 1988. The design of experiments. Statistical Principles for Practical Application. Cambridge University Press: Cambridge, UK.

Morris, V. J. 1990. Starch gelation and retrogradation. Trends Food Sci. Technol. 2-6.

Robles, R. R., Murray, E. D., and Paredes-López, O. 1988. Physicochemical changes of maize starch during the lime-heat treatment for tortilla making. Int. J. Food Sci. Technol. 23:91-98.

Roe, R. J. 2000. Methods of X-ray and Neutron Scattering in Polymer Science. Pages 134-154. Oxford University Press: New York.

Ruan, R., Almaer, S., Huand, V. T., Perkins, P., Chen, P., and Fulcher, R. G. 1996. Relationship between firming and water mobility in starchbased food systems during storage. Cereal Chem. 73:328-332.

Sahai, D., and Jackson, D. S. 1999. Enthalpic transitions in native starch granules. Cereal Chem. 76:444-448.

Seetharaman, K., Chinnapha, N., Waniska, R. D., and White, P. 2002. Changes in textural, pasting and thermal properties of wheat buns and tortillas during storage. J. Cereal Sci. 35:215-223.

Suhendro, E. L., Almeida-Domínguez, H. D., Rooney, L. W., Waniska, R. D., and Moreira, R. G. 1998. Objective rollability for corn tortilla texture measurement. Cereal Chem. 75:320-324.

Yau, J. C., Waniska, R. D., and Rooney, L. W. 1994. Effect of food additives on storage stability of corn tortillas. Cereal Foods World 39:396402.

Yglesias, R., Parkhurst, A. M., and Jackson, D. S. 2005. Development of laboratory techniques to mimic industrial-scale nixtamalization. Cereal Chem. 82:696-701.

[Received March 18, 2005. Accepted June 21, 2005.] 